\title{
Uso de textos literários no ensino de língua italiana a estrangeiros *
}

RESUMO: O emprego de textos literários no ensino de língua e cultura italiana a estrangeiros comprova sua eficácia na medida em que favorece a aproximação entre alunos e contextos sociolingüísticos narrados. A aplicabilidade deste corpus tão variado é ainda definida pela necessidade de romper, durante o ensino do idioma, as barreiras que dificultam a compreensão do repertório lingüístico italiano, principalmente no tocante às peculiaridades espaço-temporais, tais como dialetos e regionalismos.

Este artigo pretende abordar, a partir da experiência em sala de aula, aspectos envolvidos com o uso de textos literários no ensino de língua italiana e a necessidade de ressaltar, de forma didática, diante dos alunos desta língua, as causas da diversidade e complexidade do repertório lingüístico italiano.

A Península Itálica foi, através dos tempos, ponto de passagem e de chegada para muitos povos, como os gregos que, desde a antigüidade, procuravam nas costas italianas o espaço que faltava em sua "polis". Os fenícios fundaram colônias na Sardenha, na Sicília e nas costas meridionais. Enfim, passando pelos Alpes ou pelo mar, povos

* Recebido para publicação em 1999.

** Professora do Departamento de Letras Neolatinas da Faculdade de Letras da UFRJ. 
diversos chegavam para saquear, comerciar ou estabelecer-se na Península.'

Gregos ou fenícios, árabes ou germânicos, normandos ou espanhóis formaram, século após século, a história e a cultura italiana. Este fluxo de populações deixou suas marcas lingüísticas. Por isto, é fundamental, para quem se dispõe ao estudo da língua e da cultura italiana, conhecer, dentro das possíveis fontes de pesquisa, seu processo de formação.

Ao fazer-se uma análise da relação entre a língua e a cultura italiana, cumpre, em primeiro lugar, estabelecer-se de que realidade lingüística se deve partir. É importante distinguir os diversos aspectos do repertório lingüístico italiano, principalmente quando o objetivo é didático, pois a língua, como representação social, em uma perspectiva comunicativa, deve ser apresentada ao aluno de italiano (língua estrangeira) da forma mais autêntica possível.

Logo de início, podemos partir do pressuposto de que existem as seguintes variedades lingüísticas a serem observadas: a língua italiana em suas diversas fases evolutivas, a língua italiana tal como é hoje escrita e falada na Itália, tomada em sua diversidade social e regional e a língua italiana como é falada e escrita no exterior, por comunidades ou indivíduos que a falam como resíduo da língua-mãe, na qualidade de "oriundos" italianos.

Os alunos do italiano como língua estrangeira necessitam de informações e esclarecimentos de caráter histórico-geográfico e sócio-cultural sobre esses pontos. O ensino deverá, portanto, levar em conta as influências históricas na formação do povo italiano, assim como de fatores vinculados a seu passado mais recente - migração, urbanização, industrialização - e ainda outros aspectos bastante relevantes, no que se refere ao italiano contemporâneo, - reforma de ensino, alfabetização e mass media.

'BUCCI, Onorato. La formazione etnica dell'Italia e il sorgere della cultura greco-romana nella Penisola. Roma: La Goliardica, 1992. 
Sabemos que, atualmente, os livros de ensino de língua estrangeira não se resumem a apresentar conteúdos lingüísticos, mas também culturais. Os professores, em geral, procuram oferecer dados de caráter discursivo e sociolingüístico e aspectos diversos do uso da língua.

O método de escolha de textos orais e escritos para dar suporte às aulas de língua italiana para estrangeiros, assim como de qualquer: outra língua, pode atender a diferentes objetivos. Se desejamos trabalhar uma realidade verbal mais imediata, não falta material para isto: televisão, cinema, jornais e revistas oferecem uma visão bastante atualizada da língua em seus usos mais diversos, assim como toda uma gama de empréstimos e neologismos, trazidos pelas mutações sociais e tecnológicas.

Contudo, se o objetivo didático é reconhecer o itinerário da língua italiana, em seus aspectos lingüísticos, políticos e sociais, a literatura mostra-se o campo de informação mais fértil, se levarmos em conta, principalmente, escritores veristas e meridionalistas ${ }^{2}$, que utilizam a diversidade lingüística italiana como tena de denúncia ou simples documento de registro de uma realidade sócio-cultural.

Os textos literários acompanham de forma bastante fidedigna os caminhos das sociedades $^{3}$, e no caso da Itália, permitem traçar todo um processo de definição da língua padrão, em contraste com os falares dialetais. Um exemplo relevante disto é, sem dúvida, Carlo Goldoni, escritor italiano do século XVIII, que teve como objetivo maior reformular o teatro italiano. Valorizou, através de seus textos teatrais, a convivência língua/dialeto, e a necessidade de um maior intercâmbio do povo com a cultura, dentro do complexo repertório lingüístico de seu país.

\footnotetext{
'Veristas: escritores italianos empenhados em representar a verdacle; meridionalistas: escritores italialnos que representam a realidade do sul italiano ("Meridione")

'MINERVINI, Pantaleo. La lingua letteraria del Mezzogiorno d'Italia nel Settecento. Napoli: Loffredo, 1972.
} 
Tratarei aqui, especificamente, da minha experiência didática pessoal e dos resultados alcançados no uso de textos literários para o estudo de determinados aspectos da língua italiana.

O objetivo principal da utilização de textos literários, aqui proposta, é demonstrar, através de documentação literária, aspectos relevantes da língua italiana, levando em conta a diversidade de registros, através do levantamento do léxico e da ocorrência de expressões idiomáticas, provérbios e ditos populares.

Apresento como exemplo a obra I Malavoglia, de Giovanni Verga, publicada em 1881, pela Mondadori de Roma. Este escritor (18401922), nascido na Sicília, ilha ao sul da Itália, teve como objetivo principal de sua narrativa, documentar de forma verista a vida e as dificuldades do povo siciliano, principalmente dos pescadores, personagens principais da obra em estudo. Para tanto, delegou a narração a um narrador popular, que veiculasse a cultura, a mentalidade e a linguagem do mundo representado: "Un tempo i Malavoglia erano stati numerosi come i sassi della strada vecchia di Trezza"; tutti buona e brava gente di mare..." . Além disso, adotou a narrativa de aspecto coletivo, ou seja, em que os personagens, ao lado do narrador popular, contam, através de seus testemunhos pessoais, os fatos que o escritor quer ressaltar. Define-se, assim, o aspecto de "coralidade" dos habitantes locais, uma das características mais marcantes desta obra.

A escolha deste romance prende-se a três motivos principais: possuir inegável valor literário; ser um dos melhores exemplos de escritura empenhada com as causas sociais; viabilizar o acesso dos alunos a textos em relação aos quais mostram certa dificuldade de leitura e compreensão, durante o aprendizado literário, muitas vezes por falta de um método prévio e eficiente de abordagem lingüística.

Passemos agora a descrever, em linhas gerais, de que forma se desenvolveram as atividades didáticas ligadas a este romance. Em

\footnotetext{
"Trezza: pequena cidade de pescadores a poucos quilòmetros da Catania (Sicília).

${ }^{5}$ VERGA, G. I Malavoglia. Roma: Mondadori, 1986, p. 6.
} 
primeiro lugar, foi fundamental uma leitura anterior, voltada para temas já definidos, por parte dos alunos, divididos por grupos constituídos de dois integrantes. Foram selecionados alguns capítulos, obedecendo a critérios de interesse, ou seja, constituindo amostras de texto que concentrassem maior número de fatos a serem observados.

Antes de iniciarmos a análise propriamente dita dos textos, foram pesquisadas pelos alunos e complementadas em sala de aula, informações interessantes e curiosas sobre o espaço em que se localiza a narrativa, a Sicília, assim como sobre o autor e sua obra, que auxiliaram a compreensão global e enriqueceram os comentários. Além disto, atividades extra-classe como a exposição do filme baseado na obra, La terra trema, produzido por Luchino Visconti em 1948, motivaram bastante a turma, tendo dado margem, posteriormente, a outros trabalhos, como uma análise comparativa entre o discurso literário e o discurso fílmico ou cinematográfico.

O trabalho passou por etapas desenvolvidas pelos grupos, que se reuniram previamente, com tarefas que convergiram para as exposições em aula, com a seguinte distribuição: Grupo I: leitura e identificação de elementos extra-textuais; Grupo II: descrição do ambiente sócio-cultural, pela observação de fatos e personagens; Grupo III: abordagem de aspectos sociolinguísticos, pela análise formal e semântica do léxico de escolha.

O trabalho foi, assim, desenvolvido em módulos, de acordo com os aspectos abordados e com os temas específicos expostos em sala de aula, como por exemplo:

a) Grupo I: Aspectos gerais: a) histórico-geográficos — Ilha mais extensa do Mar Mediterrâneo, a mais rica em história e arte. Seu caráter insular favoreceu um desenvolvimento histórico homogêneo, com manifestações originais no campo dos costumes, da arte e da cultura em geral. b) formação étnica - A Sicília foi dominada por diversos povos, tais como: bizantinos, normandos, árabes e espanhóis. A colonização grega foi importante, com a fundação de algumas cidades, como: Messina, Catania e Siracusa. Sua formação étnica 
contou com outros povos, como os Fenícios, que fundaram Agrigento (séculos VIII-VII a.C.)

O grupo se deteve ainda no momento histórico do texto, aprofundando de forma objetiva dados que os próprios habitantes de Acitrezza forneciam, como ocorre no primeiro capítulo, página 10: "Nel dicembre 1863...". A história narrada se desenvolve logo após a proclamação do Reino de Itália. A alusão a fatos (revolta dos vilarejos sicilianos, a guerra de 1886 contra a Áustria) e personagens de época são numerosas e, inseridas no corpo dos diálogos ou no tecido da narração, são sempre um reflexo de uma característica de época, como no capítulo $\mathrm{V}$, página 67: "...e questo era il frutto di quella rivoluzione di satanasso che aveva fatto collo sciorinare il fazzoletto tricolore dal campanile"; "... e se la prendeva con Garibaldi che metteva le tasse"; "...un reazionario di quelli che proteggono i Borboni, e che cospirava pel ritorno di Franceschello. ${ }^{\text {" }}$

Este grupo apresentou, de forma bastante organizada e didática os resultados dos aspectos extra-textuais analisados.

b) Grupo II: Elementos sócio-culturais importantes para a compreensão do enredo, dentre os quais, a religiosidade, o folclore e os costumes locais. Por exemplo: os habitantes de Trezza regulam o tempo e os fatos de sua vida através dos eventos religiosos, pois a religião é um fator de grande importância para a coesão social. O abitino della Madonna é uma espécie de escapulário ou de talismã religioso, formado por dois pedaços de lã com a imagem ou o nome da Madonna ligado a duas fitas, que as devotas levam de um lado sobre o peito, $e$ do outro sobre as costas. A forma de tratamento Don, abreviação de donno (senhor), na Sicília e no Sul italiano, em geral, é empregado comumente diante de nomes próprios.

"Denoninação popular de Francesco Il di Borbone (1839-1894), último rei das duas Sicílias, que perdeu o reino em 1861, depois da expedição de Garibaldi. 
c) Grupo III: Delineamento do perfil sociolingüístico, através do registro de provérbios, ditos populares, regionalismos. Com isso, procuroul-se vencer as dificuldades de compreensão por parte clos alunos, causadas pelas peculiaridades específicas da linguagem utilizada pelo autor, que nada mais são do que a representação autêntica da linguagem popular siciliana, variação do italiano padrão já conhecido por eles.

Faremos agora um rápido resumo dos resultados obtidos por esse grupo, a partir da análise de alguns dos capítulos escolhidos.

Elementos marcadores do contexto social, ou seja, termos que fazem referência a usos, costumes e atividades locais, como a pesca (atividade masculina) e a tecelagem (atividade feminina): "delle barche sull'acqua, e delle tegole al sole", que fazem alusão aos proprietários de barco e de casa. Desde o início se coloca uma estreita relação entre casa e barca, com efeitos estilísticos interessantes: "quella barca della casa", "quella barca rotta", "era una casa che faceva acqua da tutte le parti". Foram levantadas amostras do léxico, tais como: paranza, embarcação para a pesca costeira; burrasche, tempestade, desgraça; ganza, nó formado por um anel duplo de corda sem emenda; serrare una scotta, fixar os cabos da parte inferior da vela, que servem para estendê-la ao vento; "è fatto come i merluzzi, che abboccherebbero un chiodo arrugginito" (p.142), comparação, tirada da gíria dos pescadores; "aveva pescato un camerata che sapeva di lettere" (p.34), ressaltando-se a preferência de "pescare" no lugar de "trovare"; "La Provvidenza" si dondolava sulle onde rotte dai fariglioni " (p.47), em geral faraglioni, são escolhos altíssimos e isolados no mar di Acitrezza.

Além das referências à pesca, foram analisadas palavras ligadas à atividade feminina da tecelagem, como por exemplo: "a riempire

Provvidenza barco da familia Malavoglia 
certi cannelli (carretéis) che le servivano per l'ordito (trabalho de tecelagem) della settimana" (p.22); Rocco non era più alto di questa conocchia (roda de fiar, onde se põe a lã) (p.56)".

É importante ressaltar que, para a pesquisa do léxico verghiano, foram necessárias consultas a dicionários específicos, devido à peculiaridade dos vocábulos envolvidos, principalmente no tocante a palavras de caráter regional, como por exemplo: speciale (or. fil. lat. Specialis - excelente, especialista), que originou em italiano o uso de speciale como farmacista (farmacêutico). No final da Idade Média, speziale era o mercador de especiarias. A arte dos médicos e dos speziali foi uma das Sete Artes Maiores; gruppo (or. fil. lat.-groppo, nodo (nó) ); deschetto (or. fil .lat. - banco de sapateiro; ital.-tavola (mesa), diminutivo de modéstia); baiocco (or. fil. lat. - moeda de baixo valor em uso nos Estados Pontifícios, depois ampliada ao significado de dinheiro em geral-denaro); insaccato (or. fil. lat.- dentro il sacco, que significa entre as nuvens); buffata (or. fil. lat. deriv. de buffare - sopro repentino de vento); beccaio (or. fil. lat. beccus-bico, fazendo referência talvez às aves de rapina, que significa açougueiro); sciara (or. fil.- vocábulo siciliano de origem árabe, para a crosta formada sobre o solo pelas torrentes de lava do Etna, que resfriandose, formam um extrato de rocha negra e dura, que depois de anos pode fertilizar-se novamente.deslizar. v. sciare - ital. deslizar). ${ }^{8}$

Após um primeiro levantamento do léxico concernente aos hábitos e atividades dos personagens, passou-se a destacar determinados aspectos lingüísticos, também ligados à atmosfera local. Nesta fase, procuroul-se atender às necessidades de conhecimento do conteúdo linguístico (léxico e estrutura discursivo-gramatical), respaldado pelos estudos de caráter sócio-cultural.

Quanto à dimensão linguística propriamente dita, foram destacados os seguintes tópicos, dos quais faremos uma síntese, para maior objetividade e compreensão:

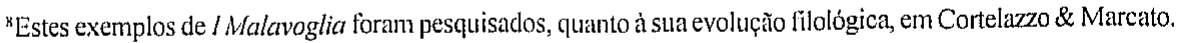
Dizionario etimologico dei dialetri italiani. Torino: UTET, 1997.
} 
1. Particularidades discursivas: uso do discurso indireto livre, uma solução intermediária entre o discurso direto e o tradicional indireto. As palavras e os pensamentos dos personagens, de caráter profundamente popular, são transmitidas espontaneamente sem a fórmula "de dizer" que introduz geralmente o discurso indireto (verbos dicendi como: dizer, afirmar, pensar etc.), como no exemplo da página 147:

"Una casa senza donna non poteva andare; ma la donna bisognava che avesse il giudizio nelle mani, come s'intendeva lei; e non fosse di quelle fraschette che pensano a lisciarsi e nient'altro, 'coi capelli lunghi e il cervello corto', ché allora un povero marito se ne va sott'acqua come compare Bastianazzo, buon'anima."

O emprego de uma forma enfática como buon'anima (boa alma) basta às vezes para assinalar, dentro do discurso indireto tradicional, a presença do discurso indireto livre.

2. Figuras de retórica e de linguagem: comparações, metáforas, eufemismos e aliterações, entre outras, produzem efeitos de grande significação ambiental, como exemplificamos a seguir: "Intanto la Provvidenza era scivolata in mare come un 'anitra" (p. 117) (No entanto a Provvidenza rodopiou no mar como um pato); "Il mare si udiva muggire" (p. 23) (O mar se ouvia mugir); "Ma Dio non gliene diede giorni lunghi..." (p.19) (Mas Deus não lhe deu dias longos).

3. Campos semânticos: conjunto de elementos lexicais específicos componentes de campos predominantes, como mare (pesca) e cielo (stelle): "si udiva il mare che russava li vicino, e ogni tanto sbuffava, come uno che si volte e rivolti pel letto" (p.77); "Le stelle ammiccavano più forte, quasi s'accendessero, e i tre re scintillavano sui fariglioni colle braccia in croce, come Sant'Andrea" (p.108). É importante ressaltar o antropomorfismo que envolve principalmente a figura do mar, isto é, a maneira como o escritor atribuiu formas e qualidades humanas a um elemento da natureza, e a dimensão espacial sugerida pela frequente citação das constelações. 
4. Referências a códigos extra lingüísticos, além do código linguístico (discursos políticos, discursos dos poderosos, fofocas e intrigas do povo em geral), os personagens do romance apresentam um código gestual próprio: mettersi le mani nei capelli (passar a mão pelos cabelos); tenere le mani sui ventri (ter as mãos sobre o ventre); nascondere le mani sotto il grembiule (it. grembiale) (esconder as mãos sob o avental); voltarsi le spalle (dar as costas); mettere fuori le scope (botar para fora as vassouras).

5. Nomes e patronímicos: antropônimos e topônimos ocorrem de maneira bastante especial no texto: substantivos, adjetivos ou locuções atributivas unem-se ao nome para melhor determiná-1o ou qualificá10: "Persino la finestra di compare Alfio, quello del carro dell' 'asino, era aperta" (p.48); "...e alla paranza di padron Fortunato Cipolla" (p.89) (personagem que diz bobagens, justificando o epíteto Cipolla, de "cipollata" - palhaçada ou extravagância); "La Mangiacarubbe, quando al lavatoio c'era anche..." (p.69) (Apelido usado como alusão injuriosa, do termo italiano 'ngiuria, referindo-se à pobreza do alimento dado aos cavalos, ou seja, a carubba = alfarroba); " e del sindaco Giufà, che si lasciava menare per il naso" (p.123). Giufà é um personagem imaginário e legendário na Sicília, cujo apelido se dá, em geral, a pessoas idiotas.

6. Adágios e expressões formulaicas: foram destacadas aqui as fórmulas expressivas convencionais (ditos populares, provérbios, regionalismos), próprias de grupos restritos de pessoas, ligadas a condições sociais ou profissões, como por exemplo o "gergo dei pescatori" (A gíria dos pescadores): "è fatto come $i$ merluzzi, che abboccherebbero un chiodo arrugginito" (é como as merluzas, que abocanhariam até um prego enferrujado); outras ainda pertencem à linguagem do povo em geral: "se la mette in tasca" (a coloca no bolso - consegue controlar); "dire corna" (dizer chifres - falar mal); "buone lane" (boas lãs - tipos pouco recomendáveis); "quelli che 
mangiano il pane del re". (aqueles que comem o pão do Rei - os dependentes do Estado).

A predominância de provérbios explica-se pelo caráter popular e tradicional dos personagens, principalmente do membro mais idoso da família Malavoglia, Padron 'Ntoni. Como exemplo, citem-se: "donna di telaio, gallina di pollaio e triglia di gennaio", significando que a mulher trabalhadeira, a galinha criada em galinheiro e a trilha pescada em janeiro são as melhores; "Lu muttu di l'anticu mai mentiu", provérbio em dialeto siciliano, afirmando que as palavras dos antigos não mentem jamais; "Quannu lu suli si 'nsacca, ventuo acqua", outro provérbio em dialeto siciliano, que corresponde a "quando o sol se esconde, vem vento ou água".

Alguns ditos populares representam com espontaneidade, aspectos ligados à moral familiar e à educação dos jovens, assim como alguns preconceitos da sociedade local. Para demonstrar, selecionamos estes dois exemplos: "La ragazza com' è educata, e la stoppa com' è filata", cujo sentido é: a fazenda adquire valor de acordo com o modo como é tecido; a moça será julgada, de acordo com a maneira como foi criada; "A donna alla finestra non far festa", ou seja, "a mulher na janela não faça festa", provérbio que define a conotação de "civettare" ( de "civetta" - coruja, mulher de má vida), ou seja, fazer-se cortejar por todos, reforçando um dito popular siciliano que diz: "farsi passare tutto il paese sotto la finestra" (fazer-se passar toda a província sob a janela).

7. Vocabulário: alguns elementos morfológicos e usos da língua definem aspectos regionais, tais como: "e la Nunziata diceva che per essere preciso come una donna..." (e Nunziata dizia que para ser como uma mulher) - preciso come - simile a; "del lumaio che rubava l'olio..." - lumaio (or. lat. lumen - luz) - lampionaio (aquele que acende a luz).

Além de todo este levantamento da linguagem siciliana exibida na obra verghiana, tentamos ressaltar, nos esquemas de análise, e 
identificar, através de pequenos particulares, a organização interna dos capítulos, que apesar de parecerem individualizados em motivos específicos, apresentam um caráter unitário, quanto a tema e objetivos de representação.

Os capítulos se desenvolvem lentamente, em coerência com o espaço narrado, em um método que alterna ação e estaticidade. Motivos e fatos diversos, apesar de heterogêneos, criam, em seu conjunto, núcleos importantes de significação, e levam adiante enredos paralelos. Os capítulos que antecedem o final, mostram resultados de situações que vieram se desenrolando pouco a pouco e o capítulo final define o significado mais profundo destes motivos que percorreram todo o texto, ou seja, o tema tratado por Verga desde a introdução: a inutilidade de fugir-se ao destino traçado desde o nascimento.

Durante nosso trabalho, realizamos, pelo aprofundamento da pesquisa, uma análise quase que "arqueológica" do espaço, observando-se a língua e suas variantes, em seu presente e seu passado. Explicando melhor, procuramos desenvolver um estudo rápido, mas não superficial, dos elementos de formação etno-lingüística do espaço narrado.

Para finalizar, podemos definir alguns resultados alcançados durante o trabalho de levantamento e análise do discurso verghiamo, além de outros não previstos inicialmente:

- Aprofundamento da leitura, levando em conta elementos extratextuais;

- Identificação dos elementos marcadores, isto é, signos que assinalam os tópicos analisados;

- Adequação dos comentários à definição teórica da diversidade linguística italiana;

- Análise comparativa com outros escritores já analisados, sob o ponto de vista temático, estrutural e semântico; 
- Realização de uma monografia, pelos grupos envolvidos, ampliando os focos de análise trabalhados.

- Utilização de método específico para a tarefa de transposição do italiano ao português.

Os procedimentos que desenvolvemos não são, é claro, os únicos possíveis, mas querem sugerir um percurso de leitura que enfrente todos os riscos que a operação apresenta, com o objetivo de desenvolver maior intimidade com a língua e a cultura italiana.

PRESENTAZIONE: L'importanza dei testi letterari utilizzati come metodo didattico nell'insegnamento della lingua italiana viene affermata dall'avvicinamento riuscito tra gli studenti ed i contesti sociolinguistici diversi. Oltre a questo, l'analisi di un corpus così vario, rende possibile una maggior facilità nella comprensione dei fatti linguistici peculiari, come i dialetti ed i regionalismi. 